\title{
Conhecimento de professores da educação básica sobre reaproveitamento dos resíduos sólidos
}

Em muitos casos, a sociedade é indiferente e omissa sobre a questão da geração de resíduos, seja por não perceber os impactos ambientais negativos por ela gerados, por falta de conhecimento, ou por entender que se trata de um problema de gestão pública. Acredita-se que é necessário maior envolvimento da sociedade na busca de soluções e que a educação ambiental pode ser a solução para um maior engajamento. Este trabalho teve como objetivo avaliar o conhecimento de professores da Educação Básica sobre o reaproveitamento de resíduos sólidos. Inicialmente a pesquisa aborda quatro tipos de reaproveitamento de resíduos: resíduos que se transformam em arte, renda, moradia e que retornam ao ciclo produtivo. Como resultado da pesquisa de levantamento, conclui-se que o conhecimento dos professores sobre reaproveitamento de resíduos sólidos é satisfatório, no entanto, práticas mais sustentáveis podem ser realizadas, tais como: separação do lixo em casa e a entrega de resíduos no ponto de coleta.

Palavras-chave: Educação Ambiental; Resíduos sólidos; Reaproveitamento.

\section{Knowledge of basic education teachers about the reuse of solid}

\section{waste}

In many cases, society is indifferent and silent on the issue of waste generation, either because it does not understand the negative environmental impacts it generates, due to lack of knowledge, or because it understands that it is a public management problem. It is believed that greater involvement of society is needed in the search for solutions and that environmental education may be the solution for greater engagement. This work aimed to evaluate the knowledge of Basic Education teachers about the reuse of solid waste. Initially, the research addresses four types of waste reuse: waste that is transformed into art, income, housing and that returns to the production cycle. As a result of the survey research, it is concluded that the knowledge of teachers about reusing solid waste is satisfactory however, more sustainable practices can be performed, such as: separation of waste at home and the delivery of waste at the collection point.

Keywords: Solid waste; Environmental education; Reuse.

Topic: Educação Ambiental

Reviewed anonymously in the process of blind peer.
Received: $11 / 02 / 2020$

Approved: 14/05/2020
Débora Carline Baierle (iD

Universidade La Salle, Brasil

http://lattes.cnpq.br/8491494609062097

http://orcid.org/0000-0001-9630-8453

debora.200710990@unilasalle.edu.br

Daniela da Cunha Silveira (ib

Universidade La Salle, Brasil

http://lattes.cnpq.br/4303784651163179

http://orcid.org/0000-0001-6691-5965

daniela.silveira0026@unilasalle.edu.br

Flávia Monaco Vieira (iD)

Universidade La Salle, Brasil

http://lattes.cnpq.br/3124206982085534

http://orcid.org/0000-0003-0851-6506

flavia.201910304@unilasalle.edu.br
Maria Geraldina Venancio

Universidade La Salle, Brasil

http://lattes.cnpq.br/6311312602932951

http://orcid.org/0000-0002-2142-9346

maria.201311546@unilasalle.edu.br
Referencing this:

GOMES JÚNIOR, C. S. V.; SILVA, C. E.. Conhecimento de professores da educação básica sobre reaproveitamento dos resíduos sólidos.

Naturae, v.2, n.1, p.40-47, 2020. DOI:

http://doi.org/10.6008/CBPC2674-6441.2020.001.0005 


\section{INTRODUÇÃO}

A problemática da geração de resíduos é um desafio para a sociedade moderna, sendo essencial o envolvimento de toda a comunidade na busca de alternativas que diminuam o acúmulo de resíduos e promovam ações sustentáveis. É necessário enaltecer a questão da sustentabilidade, destacando as responsabilidades ambientais e sociais tanto para a atual quanto para a futura geração. Apesar da importância do tema, as práticas sustentáveis ainda necessitam de avanço. Neste viés, a educação ambiental, vem como um a contribui para a sensibilização da conservação do meio ambiente, boa qualidade de vida e, sem dúvida, à sustentabilidade (CARVALHO et al., 2019).

Deste modo, o trabalho tem por objetivo avaliar o conhecimento de professores da Educação Básica acerca da reutilização de resíduos sólidos. Para tanto, foi realizado inicialmente uma pesquisa bibliográfica sobre a problemática ambiental dos resíduos sólidos e identificação de maneiras sustentáveis de reaproveitamento de resíduos urbanos, a fim de minimizar seu impacto ambiental.

No referencial teórico, abordam-se quatro tipos de reaproveitamento de resíduos: (i) resíduos que viram casas; (ii) resíduos que viram renda; (iii) resíduos que se transformam em arte, e (iv) resíduos que retornam ao ciclo produtivo. Por meio da pesquisa de levantamento, buscou-se identificar o conhecimento e atitudes de professores da Educação Básica, referentes à destinação e reaproveitamento dos resíduos sólidos.

\section{REVISÃO TEÓRICA}

Um dos problemas visíveis nos últimos anos é o descarte irregular dos resíduos sólidos que afeta diretamente o ar, o solo, a água e sua população. De acordo com Carvalho et al. (2019), o gerenciamento inadequado de resíduos sólidos acarreta consequências socioambientais negativas, podendo ser observado em grande parte das cidades brasileiras. A Constituição Federativa Brasileira de 1988 ressalta que o meio ambiente deve ser preservado e protegido. Conforme o artigo 225 da CF,

Todos têm direito ao meio ambiente ecologicamente equilibrado, bem de uso comum do povo e essencial à sadia qualidade de vida, impondo-se ao poder público e à coletividade e o dever de defendê-lo e preservá-lo para as futuras gerações.

Da mesma forma, o artigo 186, II prescreve sobre a "[...] utilização adequada dos recursos naturais disponíveis e preservação do meio ambiente". Nesse sentido, o homem faz parte da natureza e ao prejudicála, está se lesando aos poucos. Em relação a isso, Marx (citado por FOSTER, 1999) destaca,

O homem vive da natureza, isto é, a natureza é o seu corpo e tem que manter com ela um diálogo ininterrupto se não quiser morrer. Dizer que a vida física e mental do homem está ligada à natureza significa simplesmente que a natureza está ligada a si mesma, porque o homem é parte dela.

Alguns dos desafios futuros e de extrema importância em relação aos resíduos sólidos, para os municípios, são a reeducação e a sensibilização da população no processo de preservar o meio ambiente. A separação dos materiais para a reciclagem, o cuidado com os dias da coleta seletiva são atitudes para que não aconteça o descarte irregular dos resíduos e, principalmente, que as cooperativas de reciclagem tenham apoio e incentivo dos órgãos municipais para que realizem seu trabalho da melhor forma possível. 
Com o apoio da população, dos órgãos municipais e, principalmente, o trabalho das cooperativas de reciclagem pode-se obter um município mais sustentável de forma que não agrida o meio natural e garanta a utilização do mesmo em gerações futuras.

\section{Resíduos que viram casas}

Os resíduos gerados e o consumo de recursos naturais na construção civil tem sido tema de vários estudos no Brasil e em diferentes partes do mundo. Segundo Deana (2007), para cada metro quadrado de construção utilizamos grosseiramente 01 tonelada de materiais. Alguns projetos e estudos sobre a construção de moradias com o uso de material reaproveitado também vem sendo feito com frequência nas universidades e centros de estudos ambientais. Em muitos os tijolos tradicionais são utilizados garrafas PET preenchidas com areia ou solo-cimento.

Em 2012 a Fundação de Apoio à Tecnologia e Ciência - FATEC de Presidente Prudente iniciou o projeto 'CASA PET', um dos objetivos do projeto foi o de avaliar a possibilidade de reutilização de garrafas pet, que outrora iriam para o 'lixo', como material para construção das paredes e estruturas de um protótipo de casa com $24 \mathrm{~m}^{2}$. Para a execução de construção foram utilizadas 4000 garrafas pet, os idealizadores do projeto os professores Camila Pires Cremasco Gabriel, Luís Roberto Almeida Gabriel Filho e Daniel dos Santos Viais Neto, concluíram com a experiência, que o modelo é uma alternativa viável tanto do ponto de vista econômico quanto ambiental em determinadas situações, além disso, é visível que este tipo de iniciativa incentiva o ato de reaproveitar materiais tais como as garrafas de PET e despertam a curiosidade das pessoas por novas formas de construção e uso de materiais.

\section{Resíduos que viram renda}

Com o passar dos anos a sociedade foi adquirindo novos meios de sobrevivência, principalmente após a Revolução Industrial onde as pessoas buscaram outros meios de ganhar dinheiro para o sustento de suas famílias. Um destes meios foi através da coleta seletiva, onde os resíduos se tornaram a matéria prima para sustento de várias pessoas.

A renda familiar com as mudanças históricas e culturais pode alterar o contexto vivenciado. Hoje se tem várias famílias que vivem do lixo, seja por meio do trabalho informal como catadores na rua, seja através do trabalho formal nas cooperativas de reciclagem. Desta forma, muitos trabalhadores utilizam a coleta de lixo para obter renda e sanar as necessidades básicas.

No Brasil, segundo dados do Instituto Brasileiro de Geografia e Estatística (IBGE, 2010) foram recolhidas 183.488 toneladas de resíduos sólidos por dia, no ano de 2008. Dados do Instituto de Pesquisa Aplicada (IPEA, 2013), revelam que são 400 mil os catadores de resíduos no Brasil e que a maioria é formada por homens, negros e jovens. Graças a essa ocupação, quase $58 \%$ contribuem para a previdência e somente 4,5\% estão abaixo da linha da miséria. 


\section{Resíduos que se transformam em arte}

É através da arte que os artistas expressam suas diversas linguagens, utilizando a sua criatividade e comunicação para se comunicar com o seu público. A arte com reaproveitamento de materiais recicláveis se intensifica a partir do século XXI, fazendo com que os artistas tenham um pensamento ambiental no que produzem. Com isso, a produção crítica e criativa é amparada nas relações de respeito e equilíbrio ao meio ambiente (PALHACl et al., 2012).

No mundo da arte têm-se vários exemplos de artistas que utilizam materiais recicláveis em seus trabalhos, tais como: John Bassett, Vik Muniz, Eduardo Srur, entre outros. John Bassett reaproveita garrafas de vidros para a construção de seus vitrais. Tem como a luz, a textura, a linha, a estrutura, as cores e equilíbrio como algo importante para o seu trabalho.

Outro artista que se destaca é Vik Muniz, artista plástico brasileiro que elabora obras voltadas para a sustentabilidade e que em 2010, ficou conhecido no documentário intitulado 'Lixo Extraordinário' que foi apresentado o seu trabalho juntamente aos catadores de resíduos no aterro Jardim Gramacho em Duque de Caxias, no Rio de Janeiro.

Eduardo Srur é um artista visual que realiza seu trabalho com intervenções urbanas chamando atenção das pessoas para a questão ambiental e alertando sobre os problemas presenciados nas grandes metrópoles, como por exemplo, o excesso de resíduos. A arte com reciclagem é uma ferramenta importante para a sensibilização da população em relação à sustentabilidade. Através dela tem a contribuição da busca pela minimização dos problemas enfrentados no mundo atualmente.

\section{Resíduos que retornam ao ciclo produtivo}

A Política Nacional de Resíduos Sólidos (BRASIL, 2010) estipulou a logística reversa para alguns resíduos que apresentavam grande risco ao meio ambiente: agrotóxicos (seus resíduos e embalagens); pilhas e baterias; pneus; óleos lubrificantes (seus resíduos e embalagens); lâmpadas fluorescentes (de vapor, de sódio de mercúrio e de luz mista) e produtos eletroeletrônicos com seus componentes.

Através logística reversa, os resíduos retornam para o início do seu ciclo produtivo. A logística reversa é um instrumento de desenvolvimento econômico e social caracterizado por um conjunto de ações, procedimentos e meios destinados a viabilizar a coleta e a restituição dos resíduos sólidos ao setor empresarial. Por conseguinte, o reaproveitamento dentro do seu ciclo ou outra destinação final ambientalmente adequada. Empresas que adotam a logística reversa estão alinhadas ao conceito de desenvolvimento sustentável, e com o apoio da sociedade, assumem a responsabilidade socioambiental.

\section{METODOLOGIA}

Trata-se de um estudo descritivo, por meio de levantamento de dados, realizado em uma amostra de conveniência com 60 professores da Educação Básica de duas escolas, uma localizada em São Leopoldo/RS e a outra, em Cachoeirinha/RS sobre a reutilização de resíduos sólidos. 
Como instrumento de coleta de dados, utilizou-se um questionário com 10 questões fechadas. 0 questionário foi impresso, entregue ao entrevistado para preenchimento. Após os dados coletados, os resultados foram tabulados, analisados e interpretados para a realização da conclusão da pesquisa.

\section{DISCUSSÃO E RESULTADOS}

Para dar início a discussão sobre a problemática dos resíduos sólidos, as pesquisadoras registraram, no mês de setembro de 2019, por meio de fotografia algumas imagens no município de São Leopoldo (Imagens 1, 2, 3 e 4).

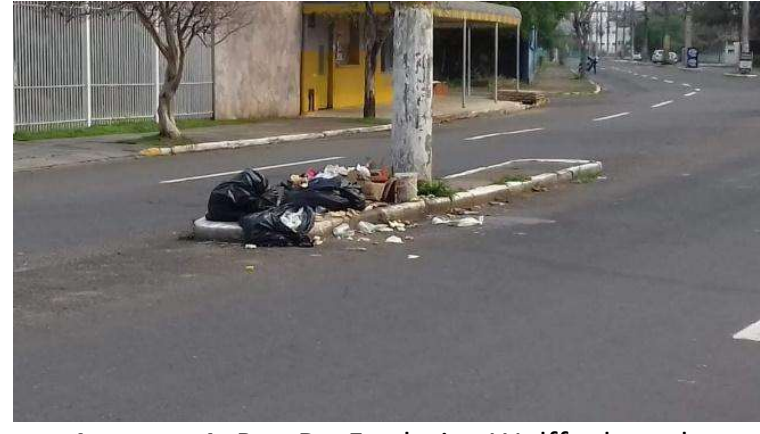

Imagem 1: Rua Dr. Frederico Wolffenbuttel.

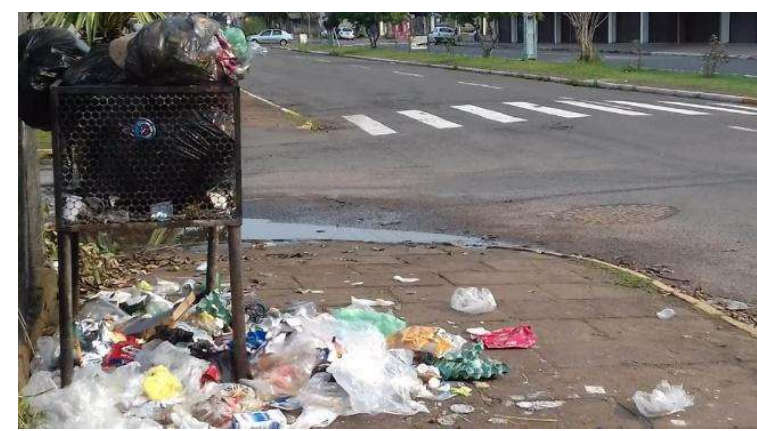

Imagem 3: Avenida Integração L.

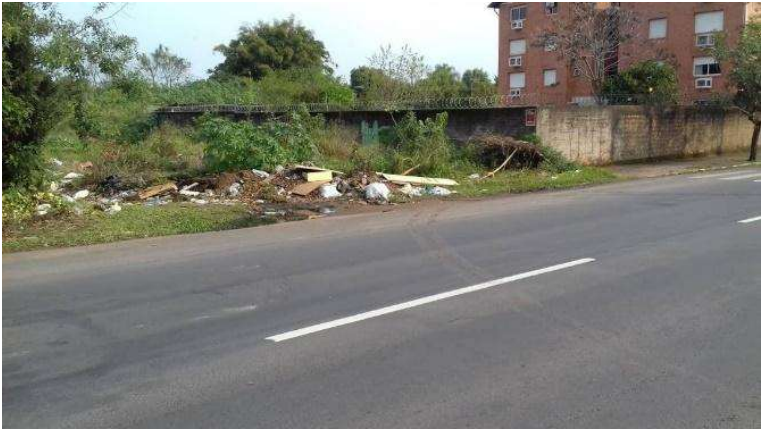

Imagem 2: Avenida Feitoria.

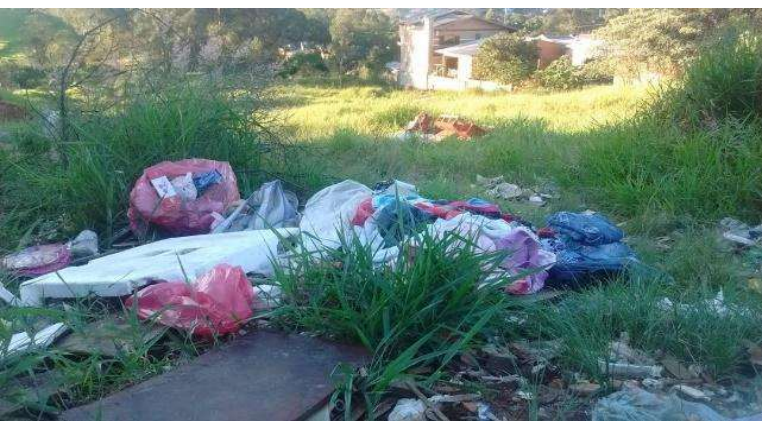

Imagem 4: Vila Santa Marta.

Nas imagens, observam-se resíduos descartados de forma irregular, espalhados pelas avenidas. A situação presenciada em São Leopoldo se repete em outros municípios gaúchos. Segundo a Política Nacional de Resíduos Sólidos (BRASIL, 2010), apesar de 30\% de todo o lixo produzido no Brasil pode ter potencial de reciclagem, apenas $3 \%$ é reaproveitado.

O acúmulo de resíduos é um problema que afeta a todos, apresentando risco a saúde humana e ao meio ambiente. Para combater esta situação se faz necessário o diálogo de toda sociedade e a educação ambiental. A pesquisa de levantamento contou com 60 respondentes, professores da Educação Básica. A seguir é apresentado o perfil demográfico dos entrevistados (Tabela 1).

Tabela 1: Perfil demográfico.

\begin{tabular}{|l|l|l|l|l|l|}
\hline \multicolumn{2}{|l|}{ Sexo } & \multicolumn{1}{l|}{ Feminino } & \multicolumn{2}{l|}{ Masculino } \\
\hline \multicolumn{2}{|l|}{} & $86,67 \%$ & $13,33 \%$ & \\
\hline Faixa Etária & 20 a 29 anos & 30 a 39 anos & 40 a 49 anos & 50 a 59 anos & 60 anos ou mais \\
\hline & $18,33 \%$ & $38,33 \%$ & $33,33 \%$ & $8,33 \%$ & $1,67 \%$ \\
\hline
\end{tabular}

A maioria dos respondentes é do sexo feminino (86,67\%), com idade entre 30 a 49 anos de idade (tabela 1). Quanto ao hábito de separar os resíduos nas suas residências, observou-se que a maioria dos 
respondentes separam os resíduos, sendo que $55 \%$ declararam que separa a maioria ou todos os resíduos e os $45 \%$ restantes não separa nada, separa pouco ou separa alguns resíduos.

A questão seguinte apresentou um pequeno conceito de Logística Reversa (LR), 'por meio da logística reversa, o material pós-uso ou consumido volta para o ciclo produtivo da empresa' e questionou sobre o conhecimento do respondente sobre empresas que utilizam a logística reversa no seu fluxo produtivo. A maioria $(51,67 \%)$ nunca ouviu falar sobre logística reversa, $46,67 \%$ conhecem uma ou duas empresas que utilizam a logística reversa e 1,67\% conhecem duas ou mais empresas (figura 2).

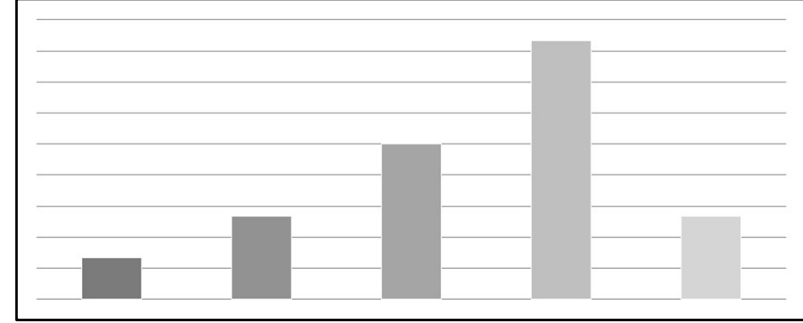

Figura 1: Hábito de separar os resíduos em casa.

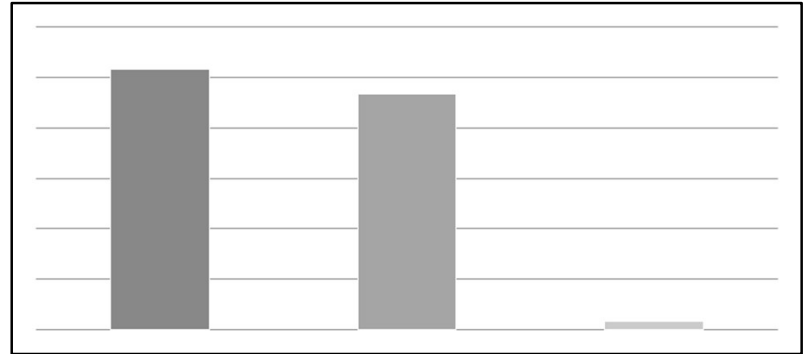

Figura 2: Empresas que utilizam a Logística Reversa no fluxo produtivo.

Quando questionado se o entrevistado entrega algum material (resíduo) em ponto de coletas e qual o material entregue, a maioria (53,33\%) afirmou não entrega, $46,67 \%$ afirmam que entregam, sendo que $11,67 \%$ destes citaram a separação da coleta seletiva como material. Desta forma, infere-se que $35 \%$ dos respondentes de fato entregam resíduos em ponto de coleta, contribuindo para a logística reversa destes materiais.

Dos $51,67 \%$, figura 2, que afirmaram que nunca ouviram falar de empresas que realizam a logística reversa em seu fluxo produtivo, $38,71 \%$ pratica a entrega de materiais em ponto de coleta. Os materiais citados, entre os respondentes que praticam a entrega de resíduos em pontos de coletas, foram: pilhas, eletrônicos/baterias, óleo de cozinha, medicamentos, vidros, tampinhas, jornal/papelão e lâmpadas (figura 3).

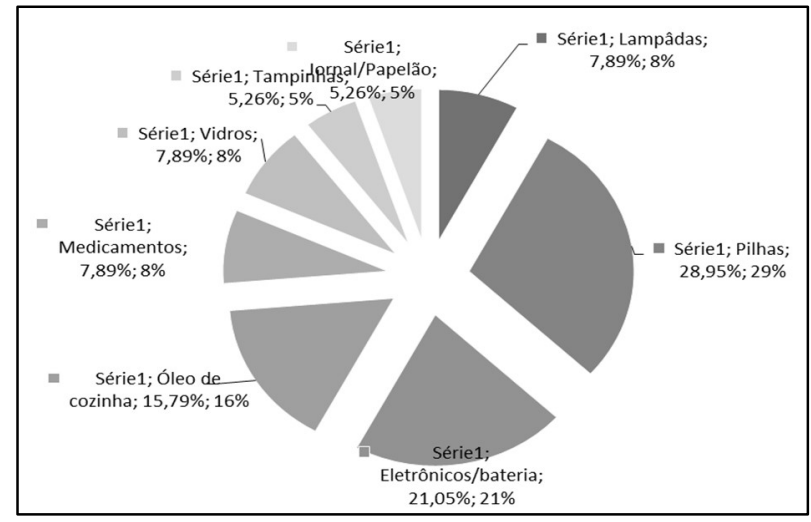

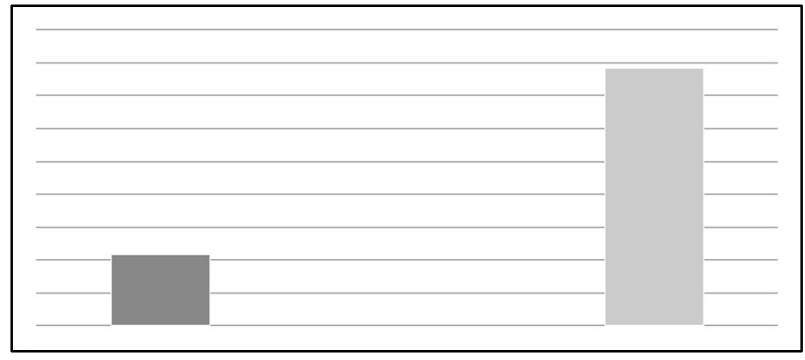

Figura 4: Geração de renda a partir de resíduos.

Figura 3: Materiais entregues em ponto de coleta.

Referente ao questionamento de que os resíduos sólidos podem gerar renda, 78,33\% afirmam que é possível e $21,67 \%$ responderam que não tem conhecimento sobre (Figura 4). Foram questionados sobre o conhecimento de projetos de casas com garrafas pets. Entre os respondentes, $85 \%$ acreditam que é possível 
construir casas a partir de garrafas pets, sendo que 13,33\% destes nunca ouviram falar sobre. Dos $15 \%$ que acreditam não ser possível, somente 3,33\% nunca ouviu falar dos projetos (figura 5).

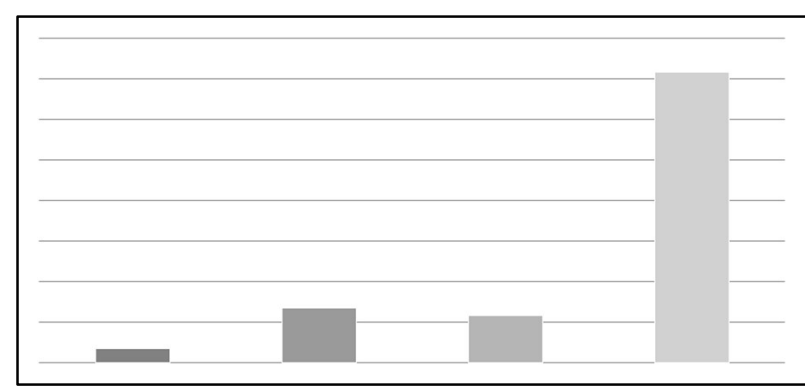

Figura 5: Projetos de construção de casas com garrafas pets.

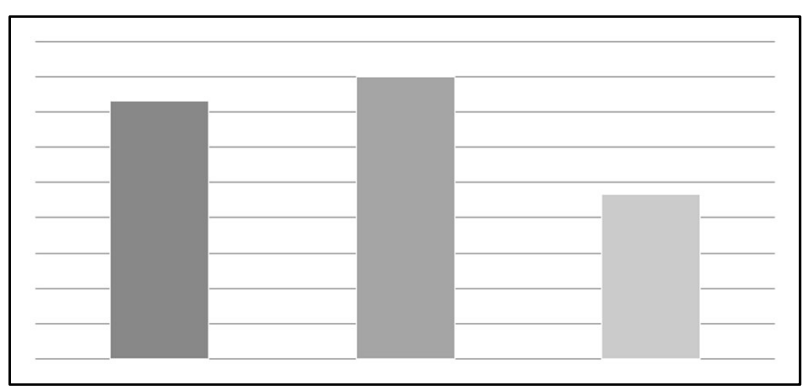

Figura 6: Artistas que utilizam resíduos.

Quando questionado sobre o conhecimento de artistas que produz artes com resíduos sólidos, a maioria dos respondentes (63,33\%) conhece algum artista, enquanto $36,67 \%$ não conhece nenhum (figura $6)$.

\section{CONCLUSÕES}

A educação ambiental pode ser uma aliada na disseminação de boas práticas no gerenciamento de resíduos. Assim como, a sensibilização da população, referente aos meios de reaproveitamento de resíduos sólidos, pode contribuir para a busca de soluções de acúmulo de resíduos urbanos.

A pesquisa avaliou o conhecimento de professores da Educação Básica acerca da reutilização de resíduos sólidos. Nas questões sobre a utilização de resíduos em projetos de construção de casas, trabalhos artísticos e geração de renda, a maioria dos respondentes tinha conhecimento. O resultado satisfatório pode ser consequência da amostragem se tratar de professores de ensino básico, ou seja, são pessoas que trabalham com o assunto em sala de aula.

Quanto ao conhecimento sobre empresas que praticam a logística reserva, o resultado foi baixo, assim como o número de entrevistados que entregam os resíduos em pontos de coleta. Este resultado pode sinalizar a ausência de disseminadores sobre a importância e as práticas da logística reversa.

Atitudes como a separação dos resíduos em casa também pode ser mais bem trabalhada, pois é o primeiro passo para a promoção de ações de utilização de resíduos, seja por reciclagem, arte, projetos e/ou logística reserva. Diminuir o acúmulo de resíduos é obrigação de todos. Acredita-se que com o diálogo na comunidade e a educação ambiental será possível obter resultados favoráveis para a redução dos resíduos sólidos e seu reaproveitamento, minimizando os impactos gerados.

\section{REFERÊNCIAS}

BRASIL. Constituição da República Federativa do Brasil de 1988. Brasília: Presidência da República, 1988.

BRASIL. Lei n. 12.305, de 2 de agosto de 2010. Institui a Política Nacional de Resíduos Sólidos; altera a Lei no 9.605 de 12 de fevereiro de 1998; e dá outras providências. Brasília: DOU, 2010.
CARVALHO, D. S.; GARCIA, T. V. L.; SILVA, V. V.; LIMA, J. P. S. Resíduos Sólidos no Brasil: Uma conexão com a relação homem/natureza, Sustentabilidade e educação ambiental. Educação Ambiental em Ação, v.68, n.18, 2019. 
DEANA, D. F.; SOUZA, U. E. L.. Habitação mais sustentável:

Levantamento do estado da arte: consumo de materiais. São Paulo: Projeto FINEP, 2007.

FOSTER, B.. Marx e o meio ambiente. In: WOOD, E.; FOSTER, B.. Em defesa da história: marxismo e pós-modernidade. Rio de Janeiro: Zahar, 1999. p.161-174.

IBGE. Instituto Brasileiro de Geografia e Estatística. Pesquisa Nacional de Saneamento Básico - PNSB 2008. Rio de Janeiro: IBGE, 2010.
IPEA. Instituto de pesquisa Aplicada. Os que sobrevivem do lixo. 77 ed. 2013.

PALHACI, M. C. J. P.; PALHACI, T. P.; HELLMEISTER, L. A. V.; NICOLA, R. L.. A importância da arte como meio de reciclagem e como formação de um novo pensamento ambiental. Proceedings of World Congress on

Communication and Arts, v.5, n.1, p.553-556, 2012.

A CBPC - Companhia Brasileira de Produção Científica (CNPJ: 11.221.422/0001-03) detém os direitos materiais desta publicação. Os direitos referem-se à publicação do trabalho em qualquer parte do mundo, incluindo os direitos às renovações, expansões e disseminações da contribuição, bem como outros direitos subsidiários. Todos os trabalhos publicados eletronicamente poderão posteriormente ser publicados em coletâneas impressas sob coordenação da Sapientiae Publishing, da Companhia Brasileira de Produção Científica e seus parceiros autorizados. Os (as) autores (as) preservam os direitos autorais, mas não têm permissão para a publicação da contribuição em outro meio, impresso ou digital, em português ou em tradução. 